\title{
Parental Attachment Style and Young Persons' Adjustment to Bereavement
}

\author{
Antigonos Sochos $^{1}$ (D) Sadia Aleem ${ }^{1}$
}

Accepted: 8 May 2021 / Published online: 26 May 2021

(c) The Author(s) 2021

\begin{abstract}
Background Previous clinical and theoretical work supports the idea that parental attachment style and complicated grief affect young persons' mental health, but empirical research investigating their impact on young person's adjustment to bereavement is lacking. Objective This study investigated the impact of parental attachment style and complicated grief on young person's adjustment to bereavement. It was hypothesised that a) parental attachment anxiety, avoidance, and complicated grief would moderate the link between bereavement experience and psychological distress in young persons and b) parental attachment style would moderate the link between parental complicated grief and psychological distress experienced by bereaved young persons.

Method This was a questionnaire-based case control study, involving two participant groups: 133 parents of young persons who had experienced the loss of the loved one and 101 parents of young persons with no bereavement experience.

Results Bereaved young persons experienced greater externalising and internalising problems than the non-bereaved only when they were raised by an anxiously attached parent, but when parental attachment anxiety was low, bereaved children had fewer problems than the non-bereaved. When parental attachment avoidance was low, bereaved children also had fewer externalising problems than the non-bereaved. Among the bereaved, high levels of parental attachment anxiety and attachment avoidance amplified the link between parental complicated grief and child post-traumatic stress, while in the presence of low parental anxiety, complicated grief was negatively associated with an immediate distressing response and numbing-dissociative symptomatology.
\end{abstract}

Conclusions Psychological vulnerability in bereaved young persons was associated with an insecure parental attachment style.

Keywords Attachment $\cdot$ Child bereavement . Complicated grief

Antigonos Sochos

antigonos.sochos@beds.ac.uk

Sadia Aleem

sadia.aleem@beds.ac.uk

1 Department of Psychology, University of Bedfordshire, Luton LU1 3JU, UK 


\section{Introduction}

The loss of a loved one is among the most distressing experiences of childhood, sometimes accompanied by significant disruptions in psychological functioning. Although most children return to their routine within a year after the loss, some suffer long-term effects (Bonnano \& Kaltman, 2001). Research suggests that the support they receive from their caregivers and the quality of the bond they form with them, are critical factors in determining children's adjustment to bereavement (Fraley \& Bonanno, 2004; Kirwin \& Hamrin, 2005). According to attachment researchers (Bowlby \& Parkes, 1970; Stroebe, Schut, \& Stroebe, 2005), as the loss of a loved one activates the attachment system, bereaved children draw on the quality of care they receive and the mental representations of their attachment figures. These are the main resources bereaved children employ, as they deal with the perceived emotional threat that the loss of a loved one signifies.

When caregivers are experienced as emotionally available and the self as worthy and loveable, bereaved children are able to retain a positive memory of the deceased and accept the finality of death (Bowlby \& Parkes, 1970). When caregivers are perceived as emotionally unavailable and the self as unwanted and vulnerable, children often find it difficult to deal with the loss (Stroebe, 2002). Numerous studies have shown that parental emotional availability depends on the quality of care parents themselves experienced as children and the quality of bond they formed with their own caregivers (Edelstein et al., 2004; Hesse $\&$ Main, 2006). These studies suggest a clear link between parental attachment security and children's mental health, although empirical research focusing specifically on bereaved children is scarce. The aim of the present study is to investigate the link between parental attachment security and the psychological adjustment of bereaved children.

\section{Parental Attachment Security and Child Distress}

Research has shown that the parental capacity to appropriately respond to their child's distress is a factor profoundly affecting the child's own ability to cope with stressors (Hesse $\&$ Main, 2006). Caregiver-child interactions are internalised in children's minds as mental representations of self and other, informing their capacity to regulate the self and form supportive relationships with others. Compared to those who receive suboptimal care, children of supportive parents tend to be guided by more benign self and other representations and attain better mental health and relationship outcomes (Madigan et al., 2013). As those representations are constructed early in life and remain deeply inscribed in the mind, they tend to impact the individual's psycho-social functioning across the life span (Thompson, 2008).

A critical factor informing a parent's capacity to support their distressed child is their childhood experience with their own caregivers - the care they received and the quality of the bond they formed with them. According to Bowlby (1982), the activation pattern of one behavioural system-attachment-affects the activation pattern in another-caregiving. An important characteristic of securely attached individuals is that they are able to regulate the negative emotions generated by perceptions of psychological threat, such as rejections, criticism, or separations. When adults have difficulties regulating the self, their capacity to support their children in regulating their own mental states is also compromised. According to attachment researchers, insecurely attached parents have limited capacity to mentalise, 
or represent their own and their child's behaviour in terms of mental states (Fonagy et al., 2002). These parents tend to be overwhelmed by their child's psychological vulnerability, fail to realise the contribution of their own responses to their child's distress, and are unable to manage effectively the child's external environment. Rooted in their childhood experience and quality of bond with their own parents, adults' capacity to reflect on the emotional world of the self and their dependents significantly impacts the child's capacity to understand and effectively manage his/her own emotional states. Studies using diverse conceptual and methodological approaches to attachment suggest that parental attachment representations relate to important parenting domains such as parental sensitivity and support provision, hostility and conflict, child maltreatment, and overall parental functioning (Jones et al., 2015). Parental attachment security has been linked with offspring's ability to regulate emotion, deal effectively with stressors, and engage in mutually satisfying social relationships (van IJzendoorn, 1995; Verhage et al., 2016).

While securely attached caregivers are likely to decode their children's cues accurately and provide a meaningful response, avoidant parents tend to downplay or ignore their children's calls for support and emotional closeness. As a result, the latter systematically suppress the expression, and ultimately the very experience of vulnerability and frustration, developing a coping strategy of self-reliance instead. Studies suggest that avoidant parents tend to under-respond when their child faces a significant stressor (Edelstein et al., 2004) and experience relatively high parenting distress and separation anxiety (Moreira et al., 2015). They also tend to report low confidence in their parenting skills (Calvo \& Bianco, 2015). Research also indicates that the link between maternal attachment avoidance and poor support provision to a distressed child is mediated by those mothers' inability to cope effectively with their own distress (Sher-Censor et al., 2020). On the other hand, anxiously attached parents tend to respond to their children's needs inconsistently, eliciting in them anxiety, ambivalence, anger, and a sense of worthlessness. These parents tend to be hostile towards their children (Wilson et al., 2007), misread their signals, interfere with exploration, and experience them as competitors for their partners' love and attention (Scher \& Dror, 2003; Selcuk et al., 2010). Finally, parents who employ both anxious and avoidant styles often neglect, abuse, or otherwise traumatise their children, eliciting a disorganised attachment response from them. Research suggests that, compared to other attachment styles, such parents experience greater separation anxiety (Vasquez et al., 2002) and are unable to detect expressions of fear in their offspring (Leerkes \& Siepak, 2006).

\section{Attachment Insecurity and Maladaptive Bereavement}

Although the above studies provide strong evidence for a link between insecure parental attachment and levels of child distress, research exploring such an association among bereaved children is lacking. In addition to parental attachment style, a child's ability to deal with bereavement has been related to the parent's own capacity to do so. Research suggests that although most adults gradually recover from the loss of a loved one, about 10-15\% continue to experience complicated grief (Bonanno et al., 2002; Prigerson et al., 1996). Being distinct from depression, anxiety, and other forms of psychopathology, this condition consists of persistent grief symptoms such as intense yearning, separation distress, and avoidance of reminders, symptoms that often lead to significant psycho-social impairment. Drawing on clinical evidence, Twomey (1995) argues that maladaptive grief is often intergenerationally transmitted, while others suggest that 
mothers still grieving for a past loss are often unable to form a bond with their newborn (O'Leary, 2009; Pantke \& Slade, 2006). These mothers tend to adopt a controlling or overprotecting parenting style hindering their child's emotional development. Zajac and Kobak (2009) report that parental inability to overcome a past loss is consistently associated with child behavioural problems from middle childhood to early adolescence, although its effects are moderated by parental attachment style.

Main and Hesse (1990) suggest that such parents suffer with an unresolved historical loss, as they are unable to integrate the painful experience of death into their mental representation of the deceased. The distressing experience remains dissociated, or segregated, from the individual's conscious awareness, but it is very much felt at an unconscious level (Bowlby, 1980). These unresolved mourners present significant lapses in their reasoning (for example, disbelief that the other person is dead) and metacognitive monitoring-that is, failure to acknowledge the contradiction between one's mental representation of the bereaved as still being alive and one's knowledge that s/he is dead (Hesse \& van Ijzendoorn, 1999; Main \& Hesse, 1990). They tend to employ both anxious and avoidant attachment strategies and develop maladaptive mechanisms of copying. Maintaining for years the possessions of the deceased as they used to be and treating a new person (e.g., a new child), or even a physical object, as a substitute for the lost loved one are examples of dysfunctional behaviours that keep these individuals attached to the past (Bowlby, 1980; Volkan, 2014).

The quality of attachment representations is a major determinant in how adults respond to a significant death (Fraley \& Bonanno, 2004; Wijngaards-de Meij et al., 2007). Unable to cope effectively with abandonment and rejection, anxiously attached individuals find it hard to manage the ultimate abandonment-the irreversible loss of death (Bowlby, 1980; Main \& Goldwyn, 1984). These individuals remain persistently distressed, often displaying a pattern of chronic grief characterised by desperate attempts to recover the lost object (Schenck, Eberle, \& Rings, 2016; Shear et al., 2007). Mancini and Bonanno (2012) claim that anxiously attached individuals experiencing complicated grief are unable to neutralise thoughts and feelings related to the deceased or utilise adaptive cognitive abilities such as appropriate discrimination and flexibility. On the other hand, repressing their need for human connection and being guided by idealised representations of self and other, avoidantly attached individuals are better able to distance themselves from the painful memory of the deceased and develop a delayed or absent grief (Bonanno \& Field, 2001). Recent studies suggest that although an avoidant response to bereavement may be adaptive in some respects, it can also become dysfunctional, particularly when the individual employs both avoidant and anxious attachment strategies (Fraley \& Bonanno, 2004). Lobb et al. (2010) argue that, in essence, complicated grief is an attachment disorder predicted by an insecure attachment style, the experience of previous loss, exposure to trauma, and the type of relationship between the sufferer and the deceased. Moreover, Dyregrov and Dyregrov (2013) point out that although maladaptive bereavement is experienced by both adults and children, identification criteria in the two groups differ significantly. Most characteristically, a traumatic element is often dominant among children, particularly when the unexpected and premature loss of a parent or sibling is involved. Although many authors use the terms interchangeably (Brown \& Goodman, 2005), others argue that complicated and traumatic grief refer to different components of maladaptive bereavement- the former refers to existential concerns stemming from over-dependency on the deceased and the latter to traumatic intrusion and avoidance (McClatchey et al., 2014). 


\section{The Present Study}

The idea that parental attachment style and complicated grief influence young persons' response to bereavement has been supported by previous clinical and theoretical work (Bowlby, 1980; Stroebe, 2002). Nonetheless, empirical research is lacking. To investigate if such parental characteristics are linked with a particular vulnerability in bereaved young persons, the present study tested the following hypotheses. First, we expected that although one year or longer after the loss, bereaved and non-bereaved young persons would report similar levels of psychological distress, parental attachment style and parental complicated grief would moderate the link between the experience of bereavement and young person behavioural problems. In particular, we hypothesised that relatively high scores in parental attachment anxiety, avoidance, and complicated grief would increase the bereaved young persons' vulnerability towards psychological distress compared to the non-bereaved. Second, we hypothesised that, among the bereaved young persons, parental attachment style would moderate the link between parental complicated grief and young person distress. As attachment style is considered a relatively stable, personality-like characteristic and complicated grief symptoms may arise as a response to a relatively recent loss, it seemed more appropriate that the former was conceptualised as the moderator (Marmarosh \& Wallace, 2016).

\section{Method}

\section{Study Design and Participants}

This was a case-control design. A total of 234 individuals took part in the study, including 133 parents of bereaved young persons and 101 parents of young persons comprising the control group. All participants were recruited from a local community in a South-Eastern English town through advertisements and snowball sampling. Advertisements were put on boards in community spaces utilised by parents such as community centres, playrooms, and local colleges. All young persons were between the ages of 6 and 16. The bereaved had recently lost a loved one, while the young persons of the control group had experienced no bereavement. All losses had occurred at least 12 months before data collection, with an average time of 28 months passed since loss $(S D=15.46)$. Forty-six percent of the bereaved young persons had lost a grandparent, 10.5\% had lost a sibling, 10\% had lost a friend, and $25 \%$ another relative they identified as very close to them.

In the bereaved group, 100 parents were female and 33 male $(M$ age $=35.5, S D=6.82)$; 45\% were white, 29\% Asian, 10\% Black African, 6\% Caribbean, and 10\% of mixed or other ethnicities; $86.5 \%$ were married or cohabiting, $2.5 \%$ divorced, and $11 \%$ single; $60 \%$ had university education, 20\% had a college qualification, 19\% had A levels or GCSE, while $1.5 \%$ had no qualifications. In the UK educational system, GCSE and A levels are subject-specific qualifications taken by high school students between the ages 14-16 and 16-19 respectively. In the non-bereaved sample, 97 parents were female and 4 male $(M$ age $=34.01, S D=7.23)$; $61 \%$ were white, $18 \%$ were Asian, $11 \%$ Black African, $2 \%$ were Black Caribbean, and $8 \%$ were of mixed or other ethnicities; $90 \%$ were married or cohabiting and $10 \%$ were single; $51 \%$ had university education, $31 \%$ had a college qualification, $15 \%$ had A levels or GCSE, while 3\% had no qualifications. 


\section{Measures}

Child behavioural and emotional problems We used the Strengths and Difficulties Questionnaire (SDQ; Goodman, 1997) to measure child psychological difficulties. This is a widely used, 25-item questionnaire assessing child emotional and behavioural problems. Those problems can be externalising, consisting of the hyperactivity and conduct subscales or internalising consisting of the emotional and peer relationship problems subscales. An additional subscale also measures the young persons' pro-social behaviour. Items are measured on a 3-point scale including 0 (not true), 1 (somewhat true), and 2 (certainly true). SDQ has been validated with various ethnic groups demonstrating good internal consistency, discriminant and predictive validity (Goodman, 2003). In the present study, all SDQ questionnaires were completed by the parents. In the bereaved sample, Cronbach's alpha $(\alpha)$ was 0.85 for the whole scale, while for the control sample $\alpha=0.82$. In the bereaved sample, $\alpha=0.69$ for externalising, $\alpha=0.73$ for internalising, and $\alpha=0.69$ for pro-social behaviour, while in the control sample, $\alpha=0.59$ for externalising, $\alpha=0.64$ for internalising and $\alpha=0.63$ for pro-social behaviour.

Child post-traumatic stress We used the Child Stress Disorders Checklist (CSDC; Saxe, Chawla, Stoddard, Kassam Adams, Courtney, Cunningham et al., 2003) to measure possible trauma due to loss in the bereaved sample. This is a 36-item questionnaire to be used with children and adolescents. The authors report evidence for the reliability and concurrent, convergent, and discriminant validity of the measure in samples of young persons experiencing traumatic events such as traffic accidents and acute burns. The scale has also been validated in diverse cultural settings (Kong et al., 2014). The questionnaire includes five items capturing the child's immediate response after the event and thirty items describing current symptoms (in the past month). Current symptoms are classified into five subscales: re-experiencing, avoidance, numbing and dissociation, increased arousal, and impairment-in-functioning. In the present study, the scale was completed by the parents of the bereaved young persons only, as parents were asked to report traumatic symptoms exclusively in relation to the loss. For the immediate response items $\alpha=0.75$ and for the 30 -item current symptom scale $\alpha=0.93$. For the re-experiencing subscale $\alpha=0.78$, for avoidance $\alpha=0.69$, for numbing and dissociation $\alpha=0.78$, for increased arousal $\alpha=0.73$ and for impairment-in-function $\alpha=0.68$.

Adult attachment We used the Experiences in Close Relationships Questionnaire (ECRQ; Brennan, Clark, \& Shaver, 1998) to measure the adult attachment style of parents. This is a widely used measure comprising two subscales-anxiety and avoidance. Each scale consists of 18 items scored on a Likert scale from 1 (agree strongly) to 7 (disagree strongly), with higher scores indicating more insecurity. Previous studies support the instruments' construct, convergent, discriminant, and predictive validity against measures of interpersonal relationships and mental health (Mikulincer \& Shaver, 2003). We used the original, rather than the revised version of the questionnaire, as we share the concerns raised by Mikulincer and Shaver (2007) regarding the latter, particularly in relation to the wording of some items and the discriminability of the two underlying factors. In the present bereaved sample, $\alpha=0.89$ for anxiety and $\alpha=0.88$ avoidance, while in the control sample $\alpha=0.92$ for anxiety and $\alpha=0.80$ for avoidance.

Adult complicated grief We used the 19-item Inventory of Complicated Grief (ICG; Prigerson et al., 1995) to measure parental complicated grief. The authors report evidence for its test-retest reliability, as well as concurrent and discriminant validity in relation to measures of depression and mental health, general health, social functioning, and role 
performance. Further research has also found a significant association between ICG and the intrusive component of post-traumatic stress (O'Connor et al., 2010). ICG is underlain by a single factor and its items are measured on a 5-point Likert scale indicating symptom frequency including 0 (never), 1 (rarely), 2 (sometimes), 3 (often), and 4 (always). In the present bereaved sample, parental complicated grief may or may not have related to the loss of the child's loved one (the deceased may or may have not been close to the parent as it was to the child); in the non-bereaved sample, it related to some important loss in the parents' past. In the bereaved sample, $\alpha=0.94$ and in the non-bereaved, $\alpha=0.90$.

\section{Procedures}

Parents were given written information about the study and were advised to consider it for at least three days before they made a decision to proceed. After providing written informed consent, participants completed and returned the questionnaires by post, email, or in person. Debrief was provided either in person, by phone, or email. Questionnaires took about 20 min to complete and there was no financial reward. Parents with more than one children were asked to report on the child they felt was most emotionally attached to the deceased. Only one parent per child took part, each self-identified as a main caregiver. No participant was excluded from the study as our exclusion criteria (time since loss for the bereaved sample and no loss ever experienced for the control sample) were made very clear to participants in the information and consent phase.

The study received ethical approval from the Psychology Research Centre of a UK university (removed for anonymity) in accordance with the ethical principles and code of conduct of the American Psychological Association and the 1964 Helsinki declaration. The study adhered to the legal requirements of the study country. The authors declare no conflict of interest.

\section{Data Analytic Plan}

To address the first hypothesis we compared the bereaved and non-bereaved groups on child psychological distress, parental attachment style and parental complicated grief using MANOVA; in addition, using hierarchical regression, we tested the moderating effects of parental attachment style and parental complicated grief on the link between bereavement status and child behavioural problems. Hierarchical regression was also used to address the second hypothesis, testing the moderating effects of parental attachment style on the link between parental complicated grief and child distress in the bereaved group. The potential confounding effect of demographic variables were controlled for in the main analyses.

\section{Results}

\section{Preliminary Results}

First, we compared the two groups on the demographic variables to identify possible confounders. The bereaved group included a significantly higher number of males, $\chi^{2}(1, \mathrm{~N}=234)=18.75, p<0.001$, and non-white, $\chi^{2}(1, \mathrm{~N}=234)=5.37$, 
$p=0.020$, than the non-bereaved group, while there were no group differences in relation to marital status, $\chi^{2}(3, \mathrm{~N}=234)=3.48, p=0.323$, educational qualifications, $\chi^{2}(3, \mathrm{~N}=234)=4.79, p=0.188$, or age, $t(232)=1.76, p=0.082$. In addition, in the bereaved group child post-traumatic stress was associated with ethnicity (Wilks $=0.91$, $F(2,130)=6.57, p=0.002$ ) and time since loss, $r(131)=-0.25, p=0.004$, while attachment anxiety was weakly correlated with age, $r(131)=-0.17, p=0.045$; no other demographic categories were related to parent or child variables (see Table 1 for descriptive statistics of study variables).

MANOVA suggested that the two samples did not differ on any attachment dimensions but, unsurprisingly, parents in the bereaved sample reported greater complicated grief $($ Wilks $=0.92, F(3,230)=6.34, p<0.001)$. The groups did not differ on either the Internalising or Externalising scores (Wilks $=0.99, F(2,231)=0.1 .05, p=0.351$ ), but when all individual SDQ subscales were entered as DVs, bereaved young persons reported more emotional problems and pro-social behaviour (Wilks $=0.92$, $F(5,228)=3.84, p=0.002)$.

\section{Attachment Style Moderating the Impact of Bereavement Experience}

To address the first hypothesis, we conducted a series of moderated regressions using child bereavement status as the IV, the Internalising, Externalising, and overall SDQ scores consecutively as DVs, and the three parental variables (attachment anxiety, attachment avoidance, complicated grief) as moderators. Parental gender, ethnicity, and complicated grief were controlled for. The assumptions for linear regression were met as scatterplots indicated a rather equal variability of standardised residuals across the range of the standardized predicted values (homoscedasticity) and p-p plots suggested an about normal distribution of residuals. In some analyses VIF values were over 10, suggesting collinearity, but when predictors were centred all VIF values were below 3.6 and all Tolerance values above 0.2 .

According to the findings (Table 2), the moderating effect of attachment anxiety was significant for both internalising and externalising problems. The effect of avoidance was significant in relation to externalising but not internalising problems $(\beta=0.10$, $p=0.328)$ or the overall SDQ score $(\beta=0.15, p=0.136)$. Interaction effect sizes were medium to small, as Cohen's $\mathrm{f}^{2}$ ranged from 0.04 to 0.02 . The moderation effects of parental complicated grief on the link between bereavement status and child symptoms were not significant. To identify whether the association between the IV and the DV was statistically significant in the high or/and low end of the moderator, we conducted post-hoc probing using the PROCESS v3.5 macro in SPSS (Hayes, 2017). According to the findings, when parental attachment anxiety scores were at least $1 S D$ above the mean $(+1 S D)$, bereaved children had higher scores in the externalising $(b=1.46$, $p=0.021)$, internalising $(b=1.59, p=0.023)$, and total SDQ $(b=4.36, p=0.008)$ scales, compared to the non-bereaved. However, when parental anxiety scores were at least $1 S D$ below the mean $(-1 S D)$, SDQ scale scores were lower in the bereaved group $(b=-4.22, p=0.003$ for SDQ total; $b=-2.64, p=0.005$ for externalising; $b=-1.77, p=0.01$ for internalising). In addition, when the parents' attachment avoidance was high $(+1 S D)$, there was no significant association between bereavement 
Table 1 Descriptive statistics of study variables

\begin{tabular}{lrrrrr}
\hline Study Variables & \multicolumn{3}{c}{ Bereaved Group } & & \multicolumn{2}{c}{$\begin{array}{l}\text { Non-Bereaved } \\
\text { Group }\end{array}$} \\
\cline { 2 - 3 } \cline { 6 - 7 } & \multicolumn{1}{c}{$M$} & \multicolumn{1}{c}{$S D$} & & $M$ & \multicolumn{1}{c}{$S D$} \\
\hline SDQ-Total & 22.77 & 8.98 & & 22.05 & 8.31 \\
SDQ-Internalising & 8.88 & 4.12 & & 8.69 & 3.66 \\
SDQ-Externalising & 8.53 & 3.95 & & 8.87 & 3.42 \\
ECRQ- Anx & 58.80 & 22.63 & & 63.49 & 22.10 \\
ECRQ-Av & 65.91 & 12.54 & & 64.96 & 17.72 \\
ICG & 38.82 & 19.58 & & 29.77 & 13.16 \\
CSDC-Immediate Response & 5.96 & 2.58 & & - & - \\
CSDC-Current Total & 36.49 & 12.56 & & - & - \\
CSDC-Re-experiencing & 8.80 & 3.38 & & - & - \\
CSDC-Avoidance & 6.02 & 2.51 & & - & - \\
CSDC-Numbing-Dissociation & 9.66 & 3.54 & & - & - \\
CSDC-Increased Arousal & 7.50 & 2.84 & & - & - \\
CSDC-Impairment-In-Function & 4.58 & 2.13 & & - & - \\
\hline
\end{tabular}

$S D Q$ Strengths and Difficulties Questionnaire, ICG Inventory of Complicated Grief, ECRQ Experiences in Close Relationships Questionnaire, Anx Anxiety, Av Avoidance

status and SDQ scores, but when avoidance was low $(-1 S D)$, bereaved children had lower externalised scores than the non-bereaved $(b=-1.55, p=0.01)$.

\section{Attachment Style Moderating the Impact of Parental Complicated Grief}

To address the second set of hypotheses, four hierarchical regressions were conducted in the bereavement sample entering parental complicated grief as the IV, SDQ and CSDC scales as DVs, and the two parental attachment dimensions as moderators. Parental ethnicity and age, as well as time since loss were controlled for. According to the findings, neither attachment dimension moderated the effects of parental complicated grief on the SDQ scales, but both anxiety and avoidance moderated such effects on CSDC (Table 3). In particular, parental anxiety moderated the effects of complicated ted grief on all child traumatic stress scales except impairment-in-function (interaction $\beta=0.14, p=0.090$ ), while parental avoidance moderated such effects on two subscales and the whole scale. The effect sizes of significant interactions were large to medium, as Cohen's $\mathrm{f}^{2}$ ranged from 0.16 to 0.04 . Moderated effects on the remaining scales were not significant, including immediate response $(F(6,126)=2.01, p=0.071)$, re-experiencing (interaction $\beta=0.16$, $p=0.077$ ), avoidance (interaction $\beta=0.12, p=0.160$ ), and impairment-in-function (interaction $\beta=0.10, p=0.263$ ).

Utilising PROCESS v3.5 as described above, we conducted post-hoc probing on the significant interactions. When parental attachment anxiety was high $(+1 S D)$, parental complicated grief was positively associated with the overall current CSDC score $(b=0.31, p=0.002)$ as well as the immediate response $(b=0.04, p=0.032)$, reexperiencing $(b=0.10, p=0.001)$, avoidance $(b=0.04, p=0.041)$, numbing-dissociation $(b=0.10, p=0.005)$, and increased arousal subscales $(b=0.06, p=0.012)$. When 
Table 2 Moderation effects of parental attachment style on the link between child bereavement status and child behavioural problems

\begin{tabular}{|c|c|c|c|c|c|}
\hline DV & Predictors & $B$ & $S E$ & B & $t$ \\
\hline \multirow[t]{7}{*}{ SDQ-Total } & Parental gender & -.07 & 1.29 & -.01 & -.05 \\
\hline & Parental ethnicity & 1.42 & .92 & .08 & 1.54 \\
\hline & ICG & .22 & .03 & .45 & $7.25 * *$ \\
\hline & Bereavement status & -1.10 & .99 & -.06 & -1.10 \\
\hline & ECRQ-Anx & .01 & .03 & .02 & .29 \\
\hline & Bereavement status by ECRQ-Anx & .13 & .04 & .25 & $3.11^{* *}$ \\
\hline & & \multicolumn{4}{|c|}{$\begin{array}{l}\text { Model: } R^{2}=.39, F(6,227)=23.83 \\
\quad p<.001\end{array}$} \\
\hline \multirow[t]{7}{*}{ SDQ_-Internalising } & Parental gender & .22 & .62 & .02 & .35 \\
\hline & Parental ethnicity & .95 & .44 & .12 & 2.15 \\
\hline & ICG & .08 & .02 & .38 & $5.82 * *$ \\
\hline & Bereavement status & -.52 & .47 & -.06 & -1.10 \\
\hline & ECRQ-Anx & .01 & .01 & .05 & .64 \\
\hline & Bereavement status by ECRQ-Anx & .05 & .02 & .22 & $2.61 * *$ \\
\hline & & \multicolumn{4}{|c|}{$\begin{array}{l}\text { Model: } R^{2}=.32, F(6,227)=19.89 \\
\quad p<.001\end{array}$} \\
\hline \multirow[t]{7}{*}{ SDQ_Externalising } & Parental gender & -.22 & .58 & -.02 & -.31 \\
\hline & Parental ethnicity & .56 & .41 & -.08 & 1.36 \\
\hline & ICG & .08 & .01 & .37 & $5.65 * *$ \\
\hline & Bereavement status & -.89 & .45 & -.12 & $-2.01 *$ \\
\hline & ECRQ-Anx & -.01 & .01 & -.01 & -.15 \\
\hline & Bereavement status by ECRQ-Anx & .07 & .02 & .31 & $3.76^{* *}$ \\
\hline & & \multicolumn{4}{|c|}{$\begin{array}{l}\text { Model: } R^{2}=.33, F(6,227)=18.66 \\
\quad p<.001\end{array}$} \\
\hline \multirow[t]{7}{*}{ SDQ_Externalising } & Parental gender & -.23 & .58 & -.02 & -.40 \\
\hline & Parental ethnicity & .49 & .41 & -.07 & 1.19 \\
\hline & ICG & .08 & .01 & .37 & $5.94 * *$ \\
\hline & Bereavement status & -.94 & .44 & -.13 & $-2.14 *$ \\
\hline & ECRQ-Av & .02 & .02 & .11 & 1.17 \\
\hline & Bereavement status by ECRQ-Av & .05 & .02 & .22 & $2.32 *$ \\
\hline & & \multicolumn{4}{|c|}{$\begin{array}{l}\text { Model: } R^{2}=.34, F(6,227)=19.31 \\
\quad p<.01\end{array}$} \\
\hline
\end{tabular}

$S D Q$ Strengths and Difficulties Questionnaire, ICG Inventory of Complicated Grief, ECRQ Experiences in Close Relationships Questionnaire, Anx Anxiety, Av Avoidance, Bereavement Status (Bereaved=1, NonBereaved $=0)$, Parental Gender $($ Male $=1$, Female $=0)$, Parental Ethnicity $($ White $=1$, Non-White $=0)$

$*<.05 * *<.01$

parental anxiety was low (-1 SD), two of these subscales were negatively associated with complicated grief-immediate response $(b=-0.04, p=0.018)$ and numbingdissociation $(b=-0.05, p=0.02)$. Moreover, when parental avoidance was high $(+1$ $S D)$, complicated grief was positively associated with the overall current CSDC score $(b=-0.28, p=0.01)$, as well as the numbing-dissociation $(b=-0.09, p=0.002)$ and increased arousal subscales $(b=-0.06, p=0.01)$. No associations between parental 
Table 3 Moderation effects of parental attachment style on the link between parental complicated grief and child post-traumatic stress among bereaved children

\begin{tabular}{|c|c|c|c|c|c|}
\hline $\mathrm{DV}$ & Predictors & $B$ & $S E$ & B & $t$ \\
\hline \multirow[t]{7}{*}{ CSDC-Immediate Response } & Parental ethnicity & .02 & .44 & .11 & 1.26 \\
\hline & Parental age & .02 & .03 & .06 & .63 \\
\hline & Time since loss & -.03 & .01 & -.15 & -1.72 \\
\hline & ICG & .01 & .01 & -.01 & -.02 \\
\hline & ECRQ-Anx & .01 & .01 & .09 & .92 \\
\hline & ICG by ECRQ-Anx & .01 & .01 & .28 & $3.32 * *$ \\
\hline & & \multicolumn{4}{|c|}{$\begin{array}{l}\text { Model: } R^{2}=.32, F(6,127)=3.15 \\
\quad p<.01\end{array}$} \\
\hline \multirow[t]{7}{*}{ CSDC-Current Total } & Parental ethnicity & 6.02 & 1.99 & -.24 & $3.01 * *$ \\
\hline & Parental age & .08 & .15 & .05 & .56 \\
\hline & Time since loss & -.17 & .06 & -.21 & $-2.64 *$ \\
\hline & ICG & .09 & .06 & .14 & 1.49 \\
\hline & ECRQ-Anx & .03 & .05 & .06 & .59 \\
\hline & ICG by ECRQ-Anx & .01 & .01 & .31 & $3.88 * *$ \\
\hline & & \multicolumn{4}{|c|}{$\begin{array}{l}\text { Model: } R^{2}=.24, F(6,126)=6.73 \\
\quad p<.001\end{array}$} \\
\hline \multirow[t]{7}{*}{ CSDC-Re-Experiencing } & Parental ethnicity & 1.03 & .55 & .15 & 1.87 \\
\hline & Parental age & .05 & .04 & .11 & 1.32 \\
\hline & Time since loss & -.04 & .02 & -.16 & $-1.96^{*}$ \\
\hline & ICG & .03 & .02 & .19 & 2.02 \\
\hline & ECRQ-Anx & .01 & .02 & .03 & .32 \\
\hline & ICG by ECRQ-Anx & .01 & .01 & .33 & $3.92 * *$ \\
\hline & & \multicolumn{4}{|c|}{$\begin{array}{l}\text { Model: } R^{2}=.20, F(6,132)=5.66 \\
p<.001\end{array}$} \\
\hline \multirow[t]{7}{*}{ CSDC_-Avoidance } & Parental ethnicity & 1.19 & .42 & .24 & $2.84 *$ \\
\hline & Parental age & -.03 & .03 & -.07 & -.79 \\
\hline & Time since loss & -.03 & .01 & -.18 & $-2.11^{*}$ \\
\hline & ICG & .01 & .01 & .12 & 1.03 \\
\hline & ECRQ-Anx & .01 & .01 & .01 & .02 \\
\hline & ICG by ECRQ-Anx & .01 & .01 & .18 & $2.819^{*}$ \\
\hline & & \multicolumn{4}{|c|}{$\begin{array}{l}\text { Model: } R^{2}=.16, F(6,126)=3.89 \\
\quad p<.01\end{array}$} \\
\hline \multirow[t]{7}{*}{ CSDC_-Numbing and Dissociation } & Parental ethnicity & 1.55 & .55 & .22 & $2.82 *$ \\
\hline & Parental age & -.01 & .04 & -.03 & -.35 \\
\hline & Time since loss & -.05 & .02 & -.22 & $-2.82 *$ \\
\hline & ICG & .03 & .02 & .14 & 1.51 \\
\hline & ECRQ-Anx & .01 & .02 & .07 & .73 \\
\hline & ICG by ECRQ-Anx & & .01 & .36 & $4.64 * *$ \\
\hline & & \multicolumn{4}{|c|}{$\begin{array}{c}\text { Model: } R^{2}=.28, F(6,126)=8.12 \\
\quad p<.001\end{array}$} \\
\hline
\end{tabular}


Table 3 (continued)

\begin{tabular}{|c|c|c|c|c|c|}
\hline DV & Predictors & $B$ & $S E$ & $\mathrm{~B}$ & $t$ \\
\hline \multirow[t]{7}{*}{ CSDC-Increased Arousal } & Parental ethnicity & 1.15 & .47 & .21 & $2.46^{*}$ \\
\hline & Parental age & .03 & .04 & .06 & .79 \\
\hline & Time since loss & -.03 & .02 & -.18 & $-2.16^{*}$ \\
\hline & ICG & .01 & .01 & .08 & .89 \\
\hline & ECRQ-Anx & .02 & .01 & .14 & 1.43 \\
\hline & ICG by ECRQ-Anx & .01 & .01 & .26 & $3.19 *$ \\
\hline & & \multicolumn{4}{|c|}{$\begin{array}{l}\text { Model: } R^{2}=.19, F(6,126)=1.99 \\
\quad p<.001\end{array}$} \\
\hline \multirow[t]{7}{*}{ CSDC-Current Total } & Parental ethnicity & 6.97 & 2.05 & .28 & $3.39 *$ \\
\hline & Parental age & .01 & .15 & .01 & .02 \\
\hline & Time since loss & -.17 & .07 & -.21 & $-2.53 *$ \\
\hline & $\mathrm{ICG}$ & .14 & .06 & .22 & $2.34 *$ \\
\hline & ECRQ-Av & -.06 & .05 & -.10 & -1.07 \\
\hline & ICG by ECRQ-Av & .01 & .01 & .19 & $2.31 *$ \\
\hline & & \multicolumn{4}{|c|}{$\begin{array}{l}\text { Model: } R^{2}=.19, F(6,126)=4.91 \\
\quad p<.001\end{array}$} \\
\hline \multirow[t]{7}{*}{ CSDC_-Numbing and Dissociation } & Parental ethnicity & 1.89 & .57 & .27 & $3.31 *$ \\
\hline & Parental age & -.04 & .04 & -.08 & -1.01 \\
\hline & Time since loss & -.05 & .02 & -.22 & $-2.64 *$ \\
\hline & ICG & .05 & .02 & .25 & $2.71 *$ \\
\hline & ECRQ-Av & -.03 & .02 & -.16 & -1.71 \\
\hline & ICG by ECRQ-Av & .01 & .01 & .23 & $2.71 *$ \\
\hline & & \multicolumn{4}{|c|}{$\begin{array}{l}\text { Model: } R^{2}=.21, F(6,126)=5.65 \\
\quad p<.001\end{array}$} \\
\hline \multirow[t]{7}{*}{ CSDC_-Increased Arousal } & Parental ethnicity & 1.33 & .47 & .23 & $2.81 *$ \\
\hline & Parental age & .01 & .04 & .01 & .06 \\
\hline & Time since loss & -.03 & .02 & -.18 & $-2.11 *$ \\
\hline & ICG & .03 & .01 & .19 & $2.03^{*}$ \\
\hline & ECRQ-Av & -.01 & .01 & -.03 & -.28 \\
\hline & ICG by ECRQ-Av & .01 & .01 & .23 & $2.65^{*}$ \\
\hline & & \multicolumn{4}{|c|}{$\begin{array}{l}\text { Model: } R^{2}=.16, F(6,126)=4.03 \\
\quad p<.01\end{array}$} \\
\hline
\end{tabular}

CSDC Child Stress Disorders Checklist, ICG Inventory of Complicated Grief, ECRQ Experiences in Close Relationships Questionnaire, Anx Anxiety, Av Avoidance, Parental Ethnicity (White=1, Non-White =0)

$*<.05 * *<.01$

CGI and CSDC scores were observed when parental attachment avoidance was low $(-1 S D)$. 


\section{Discussion}

The present findings confirm our expectation that parental attachment style would moderate the effects of bereavement experience and parental complicated grief on young persons' psychological distress. As virtually no differences in psychological problems were observed between the bereaved and the non-bereaved, current findings are consistent with previous studies suggesting that most bereaved children return to a normative level of functioning within a year after the loss (Bonnano \& Kaltman, 2001). However, our findings also suggest that bereaved young persons whose parents had an anxious attachment style may continue to experience difficulties. This is in agreement with previous research indicating that anxiously attached parents tend to provide suboptimal care and insufficient support to their children (Grossman, Fremmer- Bombik, Rudolph, \& Grossman, 1988; Verhage et al., 2016). Quality of parental care has been identified as a major determinant in children's adjustment to bereavement (Fraley \& Bonanno, 2004; Kirwin \& Hamrin, 2005). While the correlational nature of our study does not allow strong causal claims, the present findings appear to be consistent with such research.

According to the attachment literature, insecurely attached parents provide relatively poor care to their children because they have difficulty understanding and responding appropriately to their emotional states (Fonagy, 2002). As bereavement can involve overwhelming emotions in those who experience it, parental inability to support their child in regulating such emotions can facilitate the development of internalising or/and externalising problems in the young person. Although parental mentalisation, reflexive function, or another related concept was not measured in the current study, this is a reasonable hypothesis that requires further testing in future research. Guided by representations of the other as emotionally inconsistent and of the self as vulnerable, anxiously attached parents find it difficult to cope with external stressors and manage negative emotion in themselves and in their offspring. Being sensitive to rejection, these parents may perceive their bereaved children's withdrawn or challenging behaviour as refutation of their authority and ultimately disapproval of themselves as persons. Previous research suggests that anxiously attached parents may respond with hostility to such perceived rejections, making the child feel emotionally unsafe and unable to process the upset of a loss (Biringen et al., 2000).

Although quality of parental care was not directly measured in this study, its strong links with attachment security evidenced in the previous literature justifies the assumption that such a link also refers to bereaved young persons. Future studies need to confirm this, including direct measures of parental care and the parent-child bond among bereaved young persons. The fact that parental avoidance was not linked with greater psychopathology among the bereaved compared to the non-bereaved, is consistent with studies suggesting that an avoidant attachment style can sometimes provide protection against the emotional upset of bereavement (Fraley \& Bonanno, 2004). As avoidant parents tend to distance themselves emotionally from distressing events and experiences, their bereaved children may also adopt that strategy (Grossman et al., 1988). Also, although emotionally distant, avoidant parents provide relatively consistent care, potentially helping their children maintain a sense of stability as they deal with the disruption of death.

Although previous studies have shown the impact of unresolved parental grief on child mental health (Twomey, 1995; Zajac \& Kobak, 2009), the current study suggests that the critical parental characteristic protecting young persons from the effects of bereavement is attachment style. Indeed, parental attachment style also moderated the impact of parental complicated grief on child behavioural problems, a finding consistent with previous 
research involving non-bereaved children (Jacobvitz et al., 2006; Zajac \& Kobak, 2009). However, our findings specified that in bereaved young persons the only symptom area against which a relatively secure parental attachment style has a protective effect against parental complicated grief is loss-related post-traumatic stress. While previous literature suggests that complicated grief may be intergenerationally transmitted (Twomey, 1995), our findings show that parental attachment insecurity may facilitate that transmission, particularly in relation to the most traumatic aspects of the experience. Previous research has shown that the caregivers' capacity to pay attention to thoughts and feelings and facilitate emotional regulation in self and other is critical in the care of traumatised children (Akin et al., 2019). As the attachment literature suggests, the ability of insecurely attached parents to perform those functions is limited, particularly when they themselves also struggle to deal with an important loss (Pantke \& Slade, 2006).

According to our findings, both parental attachment anxiety and avoidance increase the impact of parental complicated grief on child traumatic stress. Anxiously attached parents who also struggle themselves to accept an important loss would be expected to display more exaggerated parental inconsistency between overprotecting and emotionally neglecting the child. On the other hand, avoidant parents who tend to suppress negative emotion both in themselves and their children (Edelstein et al., 2004), would be expected to do so more intensely when they also experience sadness and despair relating to an unresolved loss. Previous research has linked such coping responses with unresolved grief among young persons (Heiney et al., 1995).

Moreover, our findings indicate that the only traumatic domain not impacted upon by the interaction between parental complicated grief and attachment style was impairmentin-function, a subscale indicating difficulties with social roles and relationships. As performance in those areas is also shaped by a child's wider social environment, perhaps parental attachment security was not enough to protect bereaved young persons from a potential adverse effect of peers of the school environment. Research suggests that lack of support from one's social network is a significant factor determining the extent of an individual's traumatic response (Guay et al., 2006).

Finally, our analyses yielded some unexpected findings. Bereaved young persons with non-avoidant or non-anxious parents seemed to be less distressed than the non-bereaved, while bereaved young person with a non-anxious parent presented fewer traumatic symptoms immediately after the loss as well as fewer numbing/dissociative symptoms as a function of their parents' complicated grief. It may be the case that the absence of relational barriers linked to parental attachment insecurity, allow these relatively secure parents to get closer to their bereaved children than they would normally do and offer them additional emotional support. Securely attached parents may allow the acknowledgment, communication, and emotional processing of negative feelings so that young persons are able to utilise the bereavement experience as an opportunity for growth. This also appears in agreement with another unexpected finding in this study - the higher levels of pro-social behaviour reported by the parents of the bereaved young persons compared to the non-bereaved. 


\section{Limitations and Future Research}

Despite their significant interest, the present findings need to be approached with caution and considered in light of the study's limitations. The cross-sectional nature of the design, the use of a single measurement point and the lack of data on potential extraneous variables (e.g. parental mental health and source of complicated grief, child gender and detailed age) are factors that may have had an impact on our findings. These impose constraints on causality claims regarding the role of insecure parental attachment in children's psychological vulnerability and should be addressed in future research. Finally, there was parental gender imbalance between the sub-samples, the effects of which we attempted to limit by controlling for gender in all analyses. Future studies should also include measures of child attachment to both parents and additional parental variables such as responsiveness or type of discipline adopted, as those may clarify further the mechanisms linking parental attachment style and the psychological adjustment of bereaved young persons.

The present sample was predominantly female and well-educated and although main demographic variables were controlled for in the analyses, the extent to which the findings can be generalised to different demographic groups remains unknown. Future research needs to include demographic categories that traditionally have been underrepresented in psychological research, such as working class individuals (typically of lower educational attainment), males, and non-whites with working class males of all ethnicities being particularly excluded. Although both subsamples were more or less balanced between white and non-white participants, the category of non-white, like the category of white, is often too inclusive to be meaningful given the great cultural diversity. Previous studies suggest that both bereavement and human bonding can be experienced differently in different cultural and socio-economic contexts (Bakermans-Kranenburg, van IJzendoorn, \& Kroonenberg, 2004; Parkes, Laungani, \& Young, 2015), so future research on the issues currently addressed need to expand more systematically to such contexts.

\section{Implications of the Study}

The present findings confirm an association between insecure parental attachment style and psychological vulnerability in bereaved children. Although the study design imposes restrictions on causality claims, the present findings seem consistent with previous research suggesting a link between insecure attachment representations in the parent and difficulties of psychological adjustment in the child. While the vast majority of studies evidencing a link between insecure parental attachment, unresolved parental grief, and child psychological maladjustment have been conducted within the Adult Attachment Interview paradigm (Hesse \& van Ijzendoorn, 1999), the present findings confirm such links using a different methodological and conceptual attachment framework. The present findings highlight the relevance of attachment research in understanding the association between the parent's capacity for bonding and children's adjustment to bereavement.

Author contributions Antigonos Sochos takes responsibility for the integrity of the data and the accuracy of the data analysis. 
Open Access This article is licensed under a Creative Commons Attribution 4.0 International License, which permits use, sharing, adaptation, distribution and reproduction in any medium or format, as long as you give appropriate credit to the original author(s) and the source, provide a link to the Creative Commons licence, and indicate if changes were made. The images or other third party material in this article are included in the article's Creative Commons licence, unless indicated otherwise in a credit line to the material. If material is not included in the article's Creative Commons licence and your intended use is not permitted by statutory regulation or exceeds the permitted use, you will need to obtain permission directly from the copyright holder. To view a copy of this licence, visit http://creativecommons.org/licenses/by/4.0/.

\section{References}

Akin, B. A., Lang, K., McDonald, T. P., Yan, Y., \& Little, T. (2019). Randomized trial of PMTO in foster care: Six-month child well-being outcomes. Research on Social Work Practice, 29, 206-222. https:// doi.org/10.1177/1049731516669822

Bakermans-Kranenburg, M., van IJzendoorn, M., \& Kroonenberg, P. (2004). Differences in attachment security between African-American and white children: Ethnicity or socio-economic status? Infant Behavior and Development, 27(3), 417-433. https://doi.org/10.1016/j.infbeh.2004.02.002

Biringen, Z., Brown, D., Donaldson, L., Green, S., Krcmarik, S., \& Lovas, G. (2000). Adult Attachment Interview: Linkages with dimensions of emotional availability for mothers and their pre-kindergarteners. Attachment and Human Development, 2(2), 188-202. https://doi.org/10.1080/146167300500855 54

Bonanno, G., \& Field, N. (2001). Examining the delayed grief hypothesis across 5 years of bereavement. American Behavioral Scientist, 44(5), 798-816. https://doi.org/10.1177/00027640121956502

Bonanno, G. A., Wortman, C. B., Lehman, D. R., Tweed, R. G., Haring, M., Sonnega, J., \& Nesse, R. (2002). Resilience to loss and chronic grief: A prospective study from preloss to 18-months postloss. Journal of Personality and Social Psychology, 83, 1150-1164. https://doi.org/10.1037//0022-3514. 83.5.1150

Bonnano, G., \& Kaltman, S. (2001). The varieties of grief experience. Clinical Psychology Review, 21, 705-734. https://doi.org/10.1016/S0272-7358(00)00062-3

Bowlby, J. (1980). Attachment and loss: Loss (Vol 3). Hogarth Press.

Bowlby, J. (1982). Attachment and loss: Attachment (Vol 1). Basic Books.

Bowlby, J., \& Parkes, C. (1970). Separation and loss within the family. In E. Anthony \& C. KouperniK (Eds.), The child in his family. (pp. 110-121). Wiley.

Brennan, K., Clark, C., \& Shaver, P. (1998). Self-report measures of adult romantic attachment. In J. Simpson \& W. Rholes (Eds.), Attachment Theory and Close Relationships.Guilford Press.

Brown, E. J., \& Goodman, R. F. (2005). Childhood traumatic grief: An exploration of the construct in children bereaved on September 11. Journal of Clinical Child and Adolescent Psychology, 34, 248-325. https://doi.org/10.1207/s15374424jccp3402_4

Calvo, V., \& Bianco, F. (2015). Influence of adult attachment insecurities on parenting self-esteem: The mediating role of dyadic adjustment. Frontiers in Psychology, 6, 1461. https://doi.org/10.3389/fpsyg. 2015.01461

Dyregrov, A., \& Dyregrov, K. (2013). Complicated grief in children-the perspectives of experienced professionals. Omega Journal of Death and Dying, 67(3), 291-303. https://doi.org/10.2190/OM.67.3.c

Edelstein, R. S., Alexander, K. W., Shaver, P. R., Schaaf, J. M., Quas, J. A., Lovas, G. S., \& Goodman, G. S. (2004). Adult attachment style and parental responsiveness during a stressful event. Attachment and Human Development, 6, 31-52. https://doi.org/10.1080/146167303100001659584

Fonagy, P., Gergely, G., Jurist, E. L., \& Target, M. (2002). Affect regulation, mentalization, and the development of the self. Routledge.

Fraley, R. C., \& Bonanno, G. A. (2004). Attachment and loss: A test of three competing models on the association between attachment-related avoidance and adaptation to bereavement. Personality and Social Psychology Bulletin, 30(7), 878-890. https://doi.org/10.1177/0146167204264289

Goodman, R. (1997). The strengths and difficulties questionnaire: A research note. Child Psychology and Psychiatry and Allied Disciplines, 38(5), 581-586. https://doi.org/10.1111/j.14697610.1997.tb01545.x

Goodman, R. (2003). The Strengths and Difficulties Questionnaire (SDQ). In Vande Creek, L., and Jackson, T. L. (Eds.), Innovations in clinical practice: Focus on children \& adolescents, (pp. 109-111). Professional Resource Press/Professional Resource Exchange. 
Grossman, K., Fremmer-Bombik, E., Rudolph, J., \& Grossman, K. E. (1988). Maternal attachment representations as related to patterns of infant-mother attachment and maternal care during the first year. In R. A. Hinde \& J. Stevenson- Hinde (Eds.), Relationships within families: Mutual influences, (pp. 241-260). Clarendon.

Guay, S., Billette, V., \& Marchand, A. (2006). Exploring the links between posttraumatic stress disorder and social support: Processes and potential research. Avenues. Journal of Traumatic Stress, 19(3), 327338. https://doi.org/10.1002/jts.20124

Hayes. A. (2017). Introduction to Mediation, Moderation, and Conditional Process Analysis: A RegressionBased Approach, (2nd Ed.). Guildford Press.

Heiney, S. P., Dunaway, C., \& Webster, J. (1995). Good grieving - an intervention program for grieving children. Oncology Nursing Forum, 22(4), 649-655.

Hesse, E., \& Main, M. (2006). Frightened, threatening, and dissociative parental behavior in low-risk samples: Description, discussion, and interpretations. Development and Psychopathology, 18(2), 309-343. https://doi.org/10.1017/S0954579406060172

Hesse, E., \& van Ijzendoorn, M. H. (1999). Propensities toward absorption are related to lapses in the monitoring of reasoning or discourse during the adult attachment interview. A preliminary investigation. Attachment and Human Development, 1, 67-91. https://doi.org/10.1080/14616739900134031

Jacobvitz, D., Leon, K., \& Hazen, N. (2006). Does expectant mothers' unresolved trauma predict frightened/ frightening maternal behavior? Risk and protective factors. Development and Psychopathology, 18, 363-379. https://doi.org/10.1017/S0954579406060196

Jones, J. D., Cassidy, J., \& Shaver, P. R. (2015). Parents' self-reported attachment styles: A review of links with parenting behaviors, emotions, and cognitions. Personality and Social Psychology Review, 19(1), 44-76. https://doi.org/10.1177/1088868314541858

Kirwin, K. M., \& Hamrin, V. (2005). Decreasing the risk of complicated bereavement and future psychiatric disorders in children. Journal of Child and Adolescent Psychiatric Nursing, 18(2), 62-78. https://doi.org/10.1111/j.1744-6171.2005.00002.x

Kong, Y.-T., Zhang, J.-S., Shuai, L., Xia, W.-P., \& Wang, Z.-Y. (2014). Validity and reliability of the Chinese version of the child stress disorders checklist. Chinese Mental Health Journal, 28(6), 452457. https://doi.org/10.1007/s10803-018-3682-y

Leerkes, E., \& Siepak, K. (2006). Attachment linked predictors of women's emotional and cognitive responses to infant distress. Attachment and Human Development, 8(1), 11-32. https://doi.org/10. 1080/14616730600594450

Lobb, E. A., Kristjanson, L. J., Aoun, S. M., Monterosso, L., Halkett, G. K. B., \& Davies, A. (2010). Predictors of complicated grief: A systematic review of empirical studies. Death Studies, 34(8), 673-698. https://doi.org/10.1080/07481187.2010.496686

Madigan, S., Atkinson, L., Laurin, K., \& Benoit, D. (2013). Attachment and internalizing behavior in early childhood: A meta-analysis. Developmental Psychology, 49, 672-689. https://doi.org/10. $1037 / \mathrm{a} 0028793$

Main, M., \& Goldwyn, R. (1984). Predicting rejection of her infant from mother's representation of her own experience: Implications for the abused-abusing intergenerational cycle. Child Abuse and Neglect, 8(2), 203-217. https://doi.org/10.1016/0145-2134(84)90009-7

Main, M., \& Hesse, E. (1990). Parents' unresolved traumatic experiences are related to infant disorganized attachment status: Is frightened and/or frightening parental behavior the linking mechanism? In M. T.Greenberg, D.Cicchetti, \& E. M.Cummings (Eds.), Attachment in the preschool years: Theory research and intervention (pp. 161-182). The University of Chicago Press.

Mancini, A. D., \& Bonanno, G. A. (2012). The persistence of attachment: Complicated grief, threat, and reaction times to the deceased's name. Journal of Affective Disorders, 139(3), 256-263. https://doi. org/10.1016/j.jad.2012.01.032

Marmarosh, C. L., and Wallace, M. (2016). Attachment as moderator variable in counseling and psychotherapy with adults. In S. Maltzman (Ed.), The Oxford handbook of treatment processes and outcomes in psychology: A multidisciplinary biopsychosocial approach. (pp. 206-240). Oxford University Press.

McClatchey, I. S., Vonk, M. E., Lee, J., \& Bride, B. (2014). Traumatic and complicated grief among children: One or two constructs? Death Studies, 38(2), 69-78. https://doi.org/10.1080/07481187. 2012.725571

Mikulincer, M., \& Shaver, P. R. (2003). The attachment behavioral system in adulthood: Activation, psychodynamics, and interpersonal processes. In M. P. Zanna (Ed.), Advances in experimental social psychology (Vol. 35, pp. 53-152). New York: Academic Press.

Mikulincer, M., \& Shaver, P. R. (2007). Attachment in adulthood: Structure, dynamics, and change. New York, NY: Guilford Press. 
Moreira, H., Gouveia, M. J., Carona, C., Silva, N., \& Canavarro, M. C. (2015). Maternal attachment and children's quality of life: The mediating role of self-compassion and parenting stress. Journal of Child and Family Studies, 24(8), 2332-2344. https://doi.org/10.1007/s10826-014-0036-Z

O'Connor, M., Lasgaard, M., Shevlin, M., \& Guldin, M.-B. (2010). A confirmatory factor analysis of combined models of the Harvard Trauma questionnaire and the inventory of complicated griefrevised: Are we measuring complicated grief or posttraumatic stress? Journal of Anxiety Disorders, 24(7), 672-679. https://doi.org/10.1016/j.janxdis.2010.04.009

O'Leary, J. (2009). Never a simple journey: Pregnancy following perinatal loss. Bereavement Care, $28(2), 12-17$.

Pantke, R., \& Slade, P. (2006). Remembered parenting style and psychological well-being in young adults whose parents had experienced early child loss. Psychology and Psychotherapy: Theory, Research and Practice, 79(1), 69-81. https://doi.org/10.1348/147608305x52667

Parkes, C., Laungani, P., \& Young, B. (2015). Death and bereavement across cultures, 2nd ed. Routledge/Taylor \& Francis Group. https://doi.org/10.4324/9781315721088

Prigerson, H., Bierhals, A., Kasl, S., Reynolds, C., Shear, M., Newsom, J., \& Jacobs, S. (1996). Complicated grief as a disorder distinct from bereavement-related depression and anxiety: A replication study. The American Journal of Psychology, 153, 1484-1486. https://doi.org/10.1176/ajp.153.11. 1484

Prigerson, H. G., Maciejewski, P. K., Reynolds, C. F., III., Bierhals, A. J., Newsom, J. T., Fasiczka, A., \& Miller, M. (1995). Inventory of complicated grief: A scale to measure maladaptive symptoms of loss. Psychiatry Research, 59(1-2), 65-79. https://doi.org/10.1016/0165-1781(95)02757-2

Saxe, G., Chawla, N., Stoddard, F., Kassam-Adams, N., Courtney, D., Cunningham, K., \& King, L. (2003). Child stress disorders checklist: A measure of ASD and PTSD in children. Journal of the American Academy of Child and Adolescent Psychiatry, 42(8), 972-978. https://doi.org/10.1097/01.CHI.00000 46887.27264.F3

Schenck, L. K., Eberle, K. M., and Rings, J. A. (2016). Insecure attachment styles and complicated grief severity: Applying what we know to inform future directions. Omega: Journal of Death and Dying, 73(3):231-249. https://doi.org/10.1177/0030222815576124

Scher, A., \& Dror, E. (2003). Attachment, caregiving, and sleep: The tie that keeps infants and mothers awake. Sleep and Hypnosis, 5, 27-37.

Selcuk, E., Günaydin, G., Sumer, N., Harma, M., Salman, S., Hazan, C., \& Ozturk, A. (2010). Self-reported romantic attachment style predicts everyday maternal caregiving behavior at home. Journal of Research in Personality, 44, 544-549. https://doi.org/10.1016/j.jrp.2010.05.007

Shear, K., Monk, T., Houck, P., Melhem, N., Frank, E., Reynolds, C., \& Sillowash, R. (2007). An attachment-based model of complicated grief including the role of avoidance. European Archives of Psychiatry and Clinical Neuroscience, 257(8), 453-461. https://doi.org/10.1007/s00406-007-0745-z

Sher-Censor, E., Gur-Yaish, N., Shiff, H., et al. (2020). Mothers' attachment style and information processing of stressful situations involving their children. Journal of Child and Family Studies, 29, 30593070. https://doi.org/10.1007/s10826-020-01802-5

Stroebe, M. S. (2002). Paving the way: From early attachment theory to contemporary bereavement research. Mortality, 7(2), 127-138. https://doi.org/10.1080/13576270220136267

Stroebe, M., Schut, H., \& Stroebe, W. (2005). Attachment in coping with bereavement: A theoretical Integration. Review of General Psychology, 9(1), 48-66. https://doi.org/10.1037/1089-2680.9.1.48

Thompson, R. A. (2008). Early attachment and later development: Familiar questions, new answers. In J. Cassidy, P. R. Shaver, J. Cassidy, P. R. Shaver (Eds.), Handbook of attachment: Theory, research, and clinical applications (pp. 348-365). Guilford Press.

Twomey, J. E. (1995). Loss and replacement: Intergenerational dynamics related to a two-year old. Infant Mental Health Journal, 16(2), 144-154. https://doi.org/10.1002/1097-0355(199522)16:2\%3c144:: AID-IMHJ2280160208\%3e3.0.CO;2-A

van IJzendoorn, M. H. . (1995). Adult attachment representations, parental responsiveness, and infant attachment: A meta-analysis on the predictive validity of the Adult Attachment Interview. Psychological Bulletin, 117, 387-403. https://doi.org/10.1037/0033-2909.117.3.387

Vasquez, K., Durik, A. M., \& Hyde, J. (2002). Family and work: Implications of adult attachment styles. Personality and Social Psychology Bulletin, 28, 874-886. https://doi.org/10.1177/014672020280070 02

Verhage, M., Schuengel, C., Madigan, S., Fearon, P., Oosterman, M., Cassibba, R., \& van IJzendoorn, M. H. (2016). Narrowing the transmission gap: A synthesis of three decades of research on intergenerational transmission of attachment. Psychological Bulletin, 142(4), 337-366. https://doi.org/10.1037/bul00 00038.supp(Supplemental) 
Volkan, V. D. (2014). Father quest and linking objects: A story of the American World War II Orphans Network (AWON) and Palestinian orphans. In P. Cohen, K. M. Sossin, and R. Ruth (Eds.), Healing after parent loss in childhood and adolescence: Therapeutic interventions and theoretical considerations. (pp. 283-300). Rowman \& Littlefield.

Wijngaards-de Meij, L., Stroebe, M., Schut, H., Stroebe, W., van den Bout, J., van der Heijden, P. G. M., \& Dijkstra, I. (2007). Patterns of attachment and parents' adjustment to the death of their child. Personality and Social Psychology Bulletin, 33(4), 537-548. https://doi.org/10.1177/0146167206297400

Wilson, C. L., Rholes, W., Simpson, J. A., \& Tran, S. (2007). Labor, delivery, and early parenthood: An attachment theory perspective. Personality and Social Psychology Bulletin, 33, 505-518. https://doi. org/10.1177/0146167206296952

Zajac, K., \& Kobak, R. (2009). Caregiver unresolved loss and abuse and child behavior problems: Intergenerational effects in a high-risk sample. Development and Psychopathology, 21(1), 173-187. https://doi. org/10.1017/S095457940900011X

Publisher's Note Springer Nature remains neutral with regard to jurisdictional claims in published maps and institutional affiliations. 